\title{
PENGARUH PUSH AND PULL MOTIVATIONS TERHADAP GASTRO TOURISM DI SUMATERA BARAT
}

\author{
Sandy Pratama Arman \\ Universitas Andalas \\ psandy457@gmail.com
}

\begin{abstract}
Gastro-tourism is a recreational trip that is carried out solely or primarily to feel food in an area. Gastro-tourism is also referred to as food tourism or culinary tourism as the main destination of tourism activities. Countries with a culinary culture and diversity use this to motivate tourists to increase tourist visits. Tourist motivation is influenced by driving factors and pull factors. The driving factor is the factors that come from within the tourists themselves. Where as, pull factors are factors that come from outside the tourists, usually in the form of the condition of the destination to be visited. Every tourist has a factor that influences different motivations in carrying out tourism activities. The different types of tourism that are done make different factors that influence their motivation. One of them is culinary tourism. West Sumatra has potential culinary destinations. This type of research is explanatory. The research method used a questionnaire on 195 domestic tourists visiting West Sumatra. The sampling technique is purposive sampling based on certain criteria. This study reveals that the variables of push motivations (novelty, socialization) and pull motivations (products, main services and support services) as a whole do not significantly influence the push and pull motivations of culinary tourism in West Sumatra. In the push motivations variable social dimension. Not giving significant influence to become a tourist motivation to West Sumatra. This indicates that the social dimension is not a push motivations tourism to visit West Sumatra. Many other factors that were not examined in this study became the push motivations of tourists visiting West Sumatra.
\end{abstract}

Keywords: Motivation, push and pull factors and culinary tourism

\begin{abstract}
ABSTRAK
Gastro-tourism adalah perjalanan rekreasi yang dilakukan semata-mata atau terutama untuk merasakan makanan di suatu wilayah. Gastro-tourism juga disebut sebagai wisata makanan (food tourism) atau wisata kuliner (culinary tourism) sebagai tujuan utama dari kegiatan wisata. Negara dengan budaya kuliner dan keanekaragamannya memanfaatkan hal tersebut untuk memotivasi wisatawan demi meningkatkan kunjungan wisatawan. Motivasi wisatawan dipengaruhi oleh faktor pendorong (push factor) dan faktor penarik (pull factor). Faktor pendorong adalah faktor-faktor yang berasal dari dalam diri wisatawan itu sendiri. Sedangkan, faktor penarik adalah faktor-faktor yang berasal dari luar diri wisatawan, biasanya berupa keadaan dari destinasi yang akan dikunjungi. Setiap wisatawan memiliki faktor yang mempengaruhi motivasi yang berbeda dalam melakukan kegiatan wisata. Perbedaan jenis wisata yang dilakukan membuat berbeda pula faktor yang mempengaruhi motivasinya. Salah satunya, wisata kuliner. Sumatera Barat memliki daerah-daerah tujuan wisata kuliner yang potensial. Jenis penelitian adalah explanatory. Metode penelitian menggunakan kuesioner pada 195 wisatawan domestik yang berkunjung ke Sumatera Barat. Teknik pengambilan sampel adalah Purposive Sampling berdasarkan kriteria tertentu. Penelitian ini mengukapkan bahwa variabel push motivations (novelty, sosial) dan pulll motivations ( produk, layanan utama dan layanan
\end{abstract}


pendukung ) secara keseluruhan tidak berpengaruh secara signifikan terhadap push and pull motivations wisata kuliner di Sumatera Barat. Pada variabel push motivations dimensi sosial. Tidak memberikan pengaruh secara signifikan yang menjadi push motivation wisatawan ke Sumatera Barat. Hal ini mengindikasikan bahwa dimensi sosial bukan menjadi push motivations wisatawan untuk mengunjungi Sumatera Barat. Banyak faktor lain yang yang tidak di teliti dalam penelitian ini yang menjadi push motivations wisatawan berkunjung ke Sumatera Barat.

Kata Kunci: Motivasi, push and pull factors dan wisata kuliner

\section{PENDAHULUAN}

Kuliner sering kali dijadikan sebagai daya tarik pariwisata untuk mengundang masyarakat internasional agar termotivasi untuk datang datang mengunjungi suatu wilayah. Tak sedikit orang yang memilih untuk mengunjungi suatu wilayah dengan tujuan untuk mencicipi makanan dan juga minuman khas yang terdapat di wilayah tersebut. Inilah yang disebut dengan gastro-tourism atau disebut juga sebagai culinary tourism.

Gastro-tourism mengacu pada kunjungan wisata yang dimotivasi oleh ketertarikan terhadap makanan dan minuman di suatu wilayah ( Wolf, 2002 ). Dalam gastro-tourism, motivasi utama seseorang ketika melakukan travel adalah untuk mendapatkan pengalaman mencicipi makanan dan minuman yang dapat memberikan memori sepanjang hidup mereka. Lokasi atau tempat tujuan wisata hanya berfungsi sebagai kendaraan untuk mendapatkan pengalaman kuliner (Williams, Williams Jr, dan Oman 2014).

Sumatera Barat yang dikenal dengan kulinernya yang khas dan cara penyajian nya yang menarik hal ini dapat diharapakan menjadi motivasi bagi wisatawan untuk berkunjung ke Sumatera Barat. Akan tetapi ketika wisatawan mengambil sebuah keputusan untuk berwisata pasti telah melalui berbagai pertimbangan dan motivasi tertentu yang melandasi meskipun dalam kenyataanya hal tersebut sangat bersifat kompleks dan jarang di utarakan (implisit).

Menurut Yoon dan Usyal (2003), motivasi perjalanan wisata seseorang dibagi menjadi dua yaitu faktor pendorong dan penarik. Faktor pendorong (push factors) merupakan faktor-faktor yang terkait dengan keinginan seseorang untuk melakukan perjalanan yang berasal dari dalam dirinya (intrinsic motivation), sedangkan faktor penarik (pull factors) merupakan faktor eksternal (extrinsic motivation) yang memotivasi wisatawan untuk melakukan perjalanan wisata. Faktor penarik berhubungan dengan kualitas destinasi yang menarik bagi wisatawan (destination-spesific attributes).

Berdasarkan latar belakang diatas, maka penulis tertarik melakukan penelitian mengenai "Pengaruh Push and Pull Motivations Terhadap Gastro Tourism di Sumatera Barat".

\section{METODE KEGIATAN}

Desain Kegiatan 
Penelitian mengenai Pengaruh Push and Pull Motivations Wisatawan Terhadap Gastro Tourism di Sumatera Barat ini dilaksanakan dengan menggunakan metode non-probability sampling (pengambilan sampel secara tidak acak) dengan menggunakan teknik pengambilan sampel purposive sampling. Teknik ini dipilih karena populasi dan sampel yang diambil memiliki karakteristik tertentu. Karakteristik tersebut antara lain:

a. Wisatawan nusantara

b. Berasal dari luar Sumatera Barat

c. Berusia $\geq 17$ tahun

d. Wisatawan nusantara minimal yang sudah mengunjungi Sumatera Barat lebih dari satu kali

Apabila populasi tidak diketahui, menurut Hair dkk dalam Prawira (2010:46) merekomendasikan jumlah sampel minimal adalah 5 kali dari jumlah item pertanyaan yang terdapat dikuesioner. Variabel dalam penelitian ini terdiri dari 2 variabel bebas dan 1 variabel terikat. Total pertanyaan dalam penelitian ini adalah 39 pertanyaan, sehingga minimal ukuran sampel penelitian ini adalah 39 x $5=195$ Jadi jumlah sampel yang diambil dalam penelitian ini adalah 195 responden.Namun, besarnya sampel yang ditetapkan adalah 100 orang untuk mengurangi kesalahan.

\section{Jenis dan Teknik Pengumpulan Data}

Penelitian ini menggunakan data primer (primer source). Data yang diperoleh oleh peneliti langsung dari sumber pertama yaitu para wisatawan yang berkunjung ke Sumatera Barat. Selain itu ada data sekunder untuk mendukung penelitian yang berasal dari studi perpustakaan, jurnal, dan artikel yang berhungan dengan penelitian.

Teknik pengumpulan data yang digunakan adalah survei lapangan (field survei). Survei lapangan dilkukan dengan cara pengisian kuisioner yang telah ditentukan jawabanya, responden hanya memilih satu dari beberapa skala jawaban yang disediakan. Responden diminta untuk mengisi kuisioner yang jelah diberikan

\section{Analisis Data dan Pengujian Hipotesis}

Analisis data bertujuan untuk menginterprestasikan dan menarik kesimpulan dari hasil pengolahan data. Guna menjawab rumusan masalah dalam penelitian ini maka digunakan analisis regresi linear berganda ( Multiple Regression ) dengan program SPSS. Analisi linear berganda pada dasarnya dalah studi mengenai ketergantungan variabel dependen ( terikat ) dengan satu atau lebih variabel independen ( variabel bebas ) dengan tuuan untuk mengestimasi dan memprediksi rata-rata atau nilai variabel dependen berdasarkan nilai variabel yang diketahui ( Ghozali, 2011 )

Analisi linear berganda digunakan untuk mengetahui pengaruh ata hubungan variabel bebas ( novelty, socialization, produk, layanan utama, layanan pendukung ) terhadap wisata kuliner di sumatra barat. Bentuk matematis regresi linear berganda tersebut sebagai berkut. 


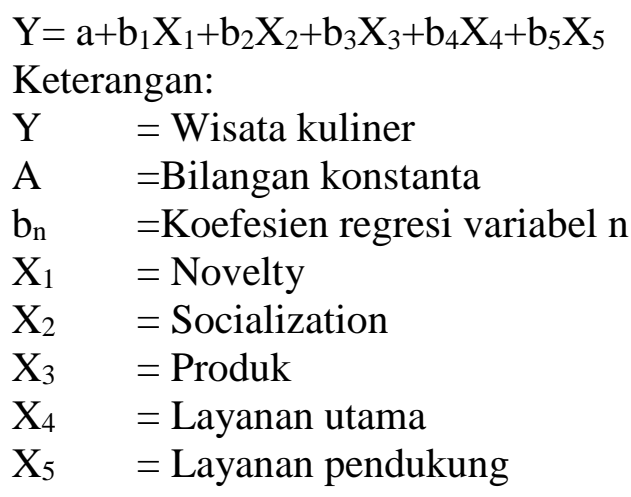

Pada analisis koefesien determinasi digunakan untuk melihat kelaakan penelitian yang dilakukan dengan memlihat variabel independen terhadap variabel dependen. Koefesien determinasi $R^{2}$ digunakan untuk mengetahui mengetahui berapa persen variasi variabel dependen dapat dijelaskan oleh variabel independen. Nilai $R^{2}$ ini terletak antara 0 dan 1.Bila nilai $R^{2}$ mendekati 0 maka berarti sedikit sekali variabel variabel yang diterangkan oleh variabel independen. Jika nilai $R^{2}$ mendekati 1 berarti semakin besar variasi yang dapat diterangkan oleh variabel independen. Jika $R^{2}$ sama dengan 0 maka variabel dependen tidak dapat dijelaskan oleh variabel independen. Regresi linear berganda sebaiknya menggunakan $R^{2}$ yang sudah dijelaskan atau tertulis Adjusted $\mathrm{R}$ Square untuk melihat koefesien determinasi karena disesuaikan dengan sejumlah variabel independen yang digunakan dimana ika variabel independen 1 ( satu ) maka menggunakan R Square dan jika melebihi 1 menggunakan Adjusted R Square ( Ghozali, 2011 ). Kelemahan mendasar penggunaan koefesien determinasi adalah bias terhadap jumlah variabel independen yang dimasukan kedalam model. Setiap tambahan variabel satu variabel independen, maka $R^{2}$ meningkat dan tidak peduli apakah variabel tersebut berpengaruh significant terhadap variabel dependent. Menurut Ghozali ( 2010 ) kareana hal tersebut banyak peneliti menganjurkan untuk menggunakan nilai adjusted $R^{2}$ pada saat mengevaluasi mana model regresi terbaik. Tidak seperti $R^{2}$ nilai adjusted dapat naik atau turun apabila satu variabel independen ditambahkan kedalam model.

Dalam membuktikan ada atau tidaknya pengaruh variabel independen terhadap variabel dependen, maka dilakukan uji t. Uji t yaitu utnuk mengetahu significant dari pengaruh variabel independent terhadap variabel dependent secara individual dan menganggap dependen yang lain konstan. Signifiant pengaruh tersebut dapat diestimasi dengan membandingkan antara nilai t tabel dengan $t$ hitung. Apabila nilai $\mathrm{t}$ hitung lebih besar dart $\mathrm{t}$ tabel maka variabel secara individual mempengaruhi variabel dependent. Begitu juga sebaliknya. Adapun langkah langkah pengujiannya sebagai berikut:

a. Menentukan taraf significant ( alpha ) sebesar 5\%.

b. Menentukan nilai significant

Nilai significant diperoleh dari hitungan SPSS

c. Jika nilai significant $>5 \%$ maka $\mathrm{H} 0$ diterima

d. Jika nilai significant $<5 \%$ maka $\mathrm{H}_{1}$ diterima 


\section{HASIL DAN PEMBAHASAN}

\section{Pengaruh Push and Pull Motivations Terhadap Gasrto Tourism di Sumatera Barat}

Analisis regresi berganda digunakan untuk melihat pengaruh semua variabel independent terhadap variabel dependen. Pada penelitian ini untuk melihat pengaruh variabel push and pull motivations yang terdiri dari dimensi: novelty, socialization untuk push motivations dan produk makanan, layanan utama dan layanan pendukung untuk push motivations terhadap wisata kuliner seperti pada tabel berikut ini.

Tabel 1. Rangkuman Hasil Analisis Regresi Berganda

\section{Coefficients $^{\mathrm{a}}$}

\begin{tabular}{|c|c|c|c|c|c|c|c|c|}
\hline \multirow{2}{*}{\multicolumn{2}{|c|}{ Model }} & \multicolumn{2}{|c|}{$\begin{array}{l}\text { Unstandardized } \\
\text { Coefficients }\end{array}$} & \multirow{2}{*}{$\begin{array}{l}\text { Standardized } \\
\text { Coefficients } \\
\text { Beta }\end{array}$} & \multirow[b]{2}{*}{$\mathrm{t}$} & \multirow[b]{2}{*}{ Sig. } & \multicolumn{2}{|c|}{$\begin{array}{l}\text { Collinearity } \\
\text { Statistics }\end{array}$} \\
\hline & & B & Std. Error & & & & Tolerance & VIF \\
\hline & (Constant) & .574 & .304 & & 1.888 & .061 & & \\
\hline & Novelty & .457 & .110 & .417 & 4.132 & .000 & .304 & 3.289 \\
\hline & Sosial & .034 & .107 & .032 & .316 & .752 & .301 & 3.323 \\
\hline & Produk & .203 & .095 & .172 & 2.134 & .034 & .478 & 2.090 \\
\hline & Layanan_Utama & .176 & .090 & .150 & 1.954 & .042 & .529 & 1.891 \\
\hline & Layanan_Pendukung & .317 & .085 & .267 & 3.705 & .000 & .595 & 1.679 \\
\hline
\end{tabular}

a. Dependent Variable: Kuliner

Pada variabel novelty (X1) terdapat pengaruh positif terhadap variabel $\mathrm{Y}$ sebesar 0.457. Hal ini menunjukan adanya hubungan searah antara novelty terhadap wisata kuliner. Sementara pada variabel sosial (X2) juga terdapat pengaruh positif terhadap variabel $\mathrm{Y}$ sebesar 0.034. Hal ini menunjukan adanya hubungan searah antara novelty terhadap wisata kuliner. Pada variabel produk (X3) terdapat pengaruh positif terhadap variabel $Y$ sebesar 0.203 . Hal ini menunjukan adanya hubungan searah antara produk terhadap wisata kuliner. Begitu juga dengan variabel layanan utama (X4) juga terdapat pengaruh positif terhadap variabel Y sebesar 0.176 . Hal ini menunjukan adanya hubungan searah antara layanan utama terhadap wisata kuliner. Sama halnya dengan varibel layanan pendukung (X5). Juga terdapat pengaruh positif terhadap variabel Y sebesar 0.317 Hal ini menunjukan adanya hubungan searah antara layanan pendukung terhadap wisata kuliner.

\section{Analisis Koefesien Determinasi}

Pengujian koefesien $R^{2}$ berguna untuk melihat seberapa besar layaknya penelitian ini yang dilakukan dengan melihat variabel bebas terhadap variabel terikat. Koefesien determinasi $R^{2}$ nilainya adalah antara $1\left(0<R^{2}<1\right) \mathrm{Jika}^{2}=$ 0 , Maka variabel dependent tidak dapat dijelaskan oleh varibel independen. Jika 
$\mathrm{R}^{2}$ mendekati 1 berarti adanya hubungan yang kuat antara variabel bebas dengan variabel terikat ( Ghozali, 2011).

Tabel 2. Koefesien Determinasi (Model Summary ${ }^{\mathrm{b}}$ )

\begin{tabular}{|c|c|c|c|c|c|c|c|c|c|c|}
\hline \multirow[b]{2}{*}{ Model } & \multirow[b]{2}{*}{$\mathrm{R}$} & \multirow[b]{2}{*}{ R Square } & \multirow[b]{2}{*}{$\begin{array}{l}\text { Adjusted } \\
\text { R Square }\end{array}$} & \multirow[b]{2}{*}{$\begin{array}{l}\text { Std. Error of } \\
\text { the Estimate }\end{array}$} & \multicolumn{5}{|c|}{ Change Statistics } & \multirow[b]{2}{*}{$\begin{array}{l}\text { Durbin } \\
\text {-Watson }\end{array}$} \\
\hline & & & & & $\begin{array}{l}\text { R Square } \\
\text { Change }\end{array}$ & F Change & df1 & df2 & $\begin{array}{l}\text { Sig. F } \\
\text { Change }\end{array}$ & \\
\hline 1 & $.648^{\mathrm{a}}$ & .420 & .404 & .60200 & .420 & 27.062 & 5 & 187 & .000 & 1.861 \\
\hline
\end{tabular}

Layanan_Utama, Produk, Sosial

b. Dependent Variable: Kuliner

Sumber Data : Olahan SPSS 2018

Pada tabel diatas dapat dilihat, nilai koefesien determinasi $\mathrm{R}^{2}$ adalah sebesar 0.404. Hal ini menunjukan bahwa hubungan variabel independent push motivations ( novelty, sosial) dan pulll motivations ( produk, layanan utama dan layanan pendukung) dengan variabel dependen ( wisata kuliner ) adalah tidak terlalu kuat. Nilai Adjusted $\mathrm{R}^{2}$ yang telah disesuaikan, nilainya adalah 0.404. Pada penelitian ini $\mathrm{R}^{2}$ tidak memperlihatkan hubungan yang sangat kuat antara variabel independen dengan variabel dependen sehingga variabel yang diteliti yakni variabel push motivations ( novelty, sosial ) dan pulll motivations ( produk, layanan utama dan layanan pendukung) mampu menjelaskan secara positif namun tidak memiliki hubungan yang terlalu kuat terhadap pengaruh wisata kuliner Sumatera Barat.

Hal ini menunjukan sangat kecilnya variabel push motivations ( novelty, sosial) dan pulll motivations ( produk, layanan utama dan layanan pendukung ) sehingga hanya mampu menjelaskan pengaruh wisata kuliner yaitu sebesar 40,4\%. Sedangkan sisanya 59,6\% di jelaskan oleh variabel lain yang tidak diteliti dalam penelitian ini. Hal ini membuktikan bahwa variabel push and pull motivations tidak terlalu kuat menjelaskan variabel wisata kuliner dengan hanya 40,4\% saja. Banyak variabel mempegaruhi intensi wisata kuliner selain variabel push and pull motivations seperti promosi, WoM, e-WoM dan variabel integreted marketing communication dan variabel lainnya.

\section{Uji T}

Uji t adalah untuk mengetahui signifikan dari pengaruh variabel bebas terhadap variabel terikat. Jika nilai signifikan $\geq 0,05$ atau $\mathrm{t}$ hitung $<\mathrm{t}$ tabel, maka Ho diterima dan Ha ditolak. Hal ini berarti variabel bebas tidak berpengaruh terhadap variabel terikat. Jika nilai signifikan $\leq 0,05$ atau $\mathrm{t}$ hitung $>\mathrm{t}$ tabel maka Ho ditolak dan Ha diterima. Berikut ini hasil pengolahan data dengan menggunakan SPSS 16.0. 
Tabel 3. Uji t: Coefficients

\begin{tabular}{|c|c|c|c|c|c|c|c|}
\hline \multirow[b]{2}{*}{ Model } & \multicolumn{2}{|c|}{$\begin{array}{l}\text { Unstandardized } \\
\text { Coefficients }\end{array}$} & \multirow{2}{*}{\begin{tabular}{|l} 
Standardized \\
Coefficients
\end{tabular}} & \multirow[b]{2}{*}{$\mathrm{t}$} & \multirow[b]{2}{*}{ Sig. } & \multicolumn{2}{|c|}{ Collinearity Statistics } \\
\hline & B & Std. Error & & & & Tolerance & VIF \\
\hline $1 \quad$ (Constant) & .574 & .304 & & 1.888 & .061 & & \\
\hline Novelty & .457 & .110 & .417 & 4.132 & .000 & .304 & 3.289 \\
\hline Sosial & .034 & .107 & .032 & .316 & .752 & .301 & 3.323 \\
\hline Produk & .203 & .095 & .172 & 2.134 & .034 & .478 & 2.090 \\
\hline Layanan_Utama & .176 & .090 & .150 & 1.954 & .042 & .529 & 1.891 \\
\hline $\begin{array}{l}\text { Layanan_Penduku } \\
\text { ng }\end{array}$ & .317 & .085 & .267 & 3.705 & .000 & .595 & 1.679 \\
\hline
\end{tabular}

a. Dependent Variable:

Kuliner

Sumber Data : Olahan SPSS 2018

Pada tabel 18 diatas dapat dilihat nilai t hitung dengan signifikan dari masing masing dimensi variabel bebas. Dimensi novelty memiliki t hitung 4,132 > dari $\mathrm{t}$ tabel 1,65279 dengan signifikan $0,000<0,05$, yang artinya dimensi novelty berpengaruh positif tehadap push factor wisata kuliner. Dimensi sosial memiliki t hitung 0,316 < dari t tabel 1,65279 dengan signifikan 0,752>0,05, yang artinya dimensi sosial berpengaruh negatif terhadap push factor wisata kuliner. Dimensi produk memiliki t hitung 2,134 > dari t tabel 1,65279 dengan signifikan 0,034< 0,05 yang artinya dimensi produk berpengaruh positif terhadap pull factor wisata kuliner. Dimensi layanan utama memiliki t hitung 1,954 > dari t tabel 1,65279 dengan signifikan $0.042<0,05$ yang artinya dimensi layanan utama berpengaruh signifikan terhadap pull factor wisata kuliner. Dimensi layanan pendukung memiliki t hitung 3,075 > dari t tabel 1,65279 dengan signifikan 0,000 <0,05 artinya dimensi layanan layanan pendukung berpengaruh signifikan terhadap pull factor wisata kuliner.

Tabel 4. Rangkuman Hasil Uji Hipotesis

\begin{tabular}{|l|l|l|l|l|l|}
\hline Variabel & T Tabel & T hitung & Sig & Beta & Keputusan \\
\hline Novelty & 1,65279 & 4.132 & .000 & .417 & Diterima \\
Sosial & 1,65279 & .316 & .752 & .032 & Ditolak \\
Produk & 1,65279 & 2.134 & .034 & .172 & Diterima \\
Layanan Utama & 1,65279 & 1.954 & .042 & .150 & Diterima \\
Layanan Pendukung & 1,65279 & 3.705 & .000 & .267 & Diterima \\
\hline
\end{tabular}

Sumber: Diolah dari kuesioner dengan SPSS 16.0 
Berdasarkan tabel 19 diatas memperlihatkan bagaimana variabel push motivations ( novelty, sosial) dan pulll motivations ( produk, layanan utama dan layanan pendukung ) secara keseluruhan tidak berpengaruh secara signifikan terhadap wisata kuliner di Sumatera Barat dengan hanya sebesar 40,4\%. Pada variabel push motivations ( sosial ) memiliki nilai signifikan di atas 0,05 sehingga tidak berpengaruh secara signifikan tetapi berpengaruh secara positif terhadap push motivations wisata kuliner di Sumatera Barat. Sedangkan untuk variabel push motivation dimensi novelty mempunyai pengaruh yang signifikan karena keil dari 0,05 dan berpengaruh positif terhadap push motivations wisata kuliner di Sumatera Barat. Untuk variabel pulll motivations ( produk, layanan utama dan layanan pendukung ) mempunyai pengaruh yang signifikan dan berpengaruh positif terhadap pull motivations wisata kuliner di Sumatera Barat.

\section{KESIMPULAN}

Penelitian ini meneliti penilaian wisatawan nusantara terhadap konsep Push and Pull Motivation Terhadap Wisata Kuliner di Sumatera Barat. Berdasarkan analisis bab IV dapat ditarik kesimpulan sebagai berikut:

Pada variabel push motivations dimensi novelty mempunyai pengaruh positif terhadap wisata kuliner di Sumatera Barat, Sedangkan variabel push motivations dimensi sosial juga mempunyai pengaruh terhadap wisata kuliner di Sumatera Barat tetapi tidak berpengaruh secara signifikan. Sedangkan variabel pull motivations dimensi produk, layanan utama dan layanan pendukung berpengaruh secara signifikan.

Pada penelitian ini dibuktikan dengan adanya pengujian hipotesis yang memperlihatkan pengaruh yang tidak kuat antara variabel push and pull motivations terhadap wisata kuliner di Sumatera Barat yang hanya mampu menjelaskan sebesar 40,4\% secara keseluruhan sementara untuk 59,6\% dijelaskan oleh variabel lain yang tidak diteliti dalam peneltian ini seperti variabel destination image, wom, e-wom, integrated marketing yang di duga mempunyai pengaruh yang kuat yang dapat menjadi motivasi wisatawan terhadap kuliner di Sumatera Barat.

Berdasarkan hasil penelitian maka dapat disarankan sebagai berikut: 1) Kepeada pengelola destinasi Sumatera Barat agar lebih meningkatkan pemasaran destinasi tentang kuliner Sumatera Barat. 2) menciptakan komunikasi yang terintegrasi antara pengelola destinasi, pemerintah, masyarakat lokal dan pengunjung sehingga terjalin kerja sama yang saling menguntungkan semua pihak sehingga memperbesar minat mereka untuk kembali mengunjung Sumatera Barat. 3) Menambahkan tema baru setiap event. Misalnya: pada event wisata kuliner, event tidak harus fokus pada kuliner saja, bisa di tambahkan event lain nya yang mengandung unsur kebudayaan daerah. Baik itu berupa acara musik atau permainan daerah. 4) Ikut sertakan pengunjung pada setiap event. Hal ini dapat membuat pengunjung akan mengingat event event yang ada di Sumatera Barat sehingga kemungkinan untuk datang kembali ke Sumatera Barat besar. 


\section{DAFTAR PUSTAKA}

Ariyanto, 2005, Ekonomi Pariwisata, Penerbit Rineka Cipta, Jakarta.

Assauri, Sofjan, 1999, Manjemen Pemasaran: Dasar, Konsep, dan Strategi, PT.Raja Grafindo Persada, Jakarta, hal. 149.

Abdul Karim, Muhammad Shahrim dan Chua, Bee Lia dan Salleh, Hamdin, (2010) Malaysia as a culinary tourism destination: international tourist's perspective. Journal of Tourism, Hospitality and Culinary Arts, 1 (3). hlm. 63-78. ISSN 1985-8914

Antón Clave, S \& Knafou, R. (2012). Gastronomy tourism and globalization. Paris:Universitat Rovira i Virgili - Tarra gona, Université Paris 1.

Besra, Eri. 2012. Potensi Wisata Kuliner Dalam Mendukung Pariwisata Di Kota Padang, Akuntansi dan Bisnis, UNIVERSITAS MUHAMMADIYAH SUMATERA UTARA.

Darmajati, RS, Istilah-istilah dunia pariwisata, Pradnya Paramita, Jakarta, 1983. Ismayanti, 2010.Pengantar Pariwisata.Jakarta, PT.Grasindo

Ike, Janita Dewi.2011. Implementasi dan Implikasi Kelembagaan Pemasaran Pariwisata Yang Bertanggung Jawab (Responsible Tourism Marketing), Jakarta, Penerbit Pinus Book Publiher Untuk Kementrian Kebudayaan dan Pariwisata Republik Indonesia.ISBN 978-602-8533-53-9

Jennifer Kim Lian Chan \& Tom Baum (2007) Motivation Factors of Ecotourists in Ecolodge Accommodation: The Push and Pull Factors, Asia Pacific Journal of Tourism Research, 12:4, 349-364

Kassean, Hemant. 2013. "Exploring Tourists Push and Pull Motivations to VisitMauritius as a Tourist Destination", African Journal of Hospitality, Tourism and Leisure Vol: 2 (3).

Kotler, Philip.2009. Manajemen Pemasaran : Analisis, Perencanaan dan Pengedalian. Jilid 1 dan 2. Edisi Millenium. Ahli Bahasa Hendra.

Mil, Rober Christie.1990.Tourism: The International Business Singapore : Prentice Hall.

Sukenti, Kurniasih (2014) Gastronomy Turism in Several Neighbor Countries of Indonesia: a Brief Review, Journal of Indonesian Tourism and Development Studies Vol.2, No.2, April, hlm.55-63

Marliyati, S. A., D. Hastuti, T. Sinaga. 2013. Eco-culinary tourism in Indonesia, dalam F. Teguh \& R. Avenzora (Ed.). Ecotourism and sustainable tourism development in Indonesia: Potentials, lesson and best practices. Ministry of Tourism and Creative Economy, PT. Gramedia, Jakarta, Indonesia. hlm. 251-301.

Pitana, I Gde. 2005. Sosiologi Pariwisata, Kajian sosiologis terhadap struktur, sistem, dan dampak-dampak pariwisata. Yogyakarta: Andi Offset.

Rusmini, Made, 2001. Manajemen Pemasaran. Yogyakarta: Andi Offset Saleh, Pengembangan pariwisata di Indonesia, UI Press, Jakarta, 1988.

Suwantoro, Gamal. 2004. Dasar-dasar Pariwisata. Penerbit Andi Yogyakarta Sarwono, Jonathan. 2012. Path Analysis dengan Spss. Penerbit PT. Elex Media.

Sekaran,U .2000. Research Methods For Bisnis, third edition, Jhon Wiley \& Sons, Inc. 
Semuel Hatane, 2007. Pengaruh Stimulus Media Iklan, Uang Saku, Usia dan Gender terhadap prilaku pembelian Impulsif ( Studi Kasus Produk Wisata), Jurnal Manajemen Pemasaran, Universitas Kristen Petra.

Simamora, Hendry. 2000. Manajemen Pemasaran International. Jakarta: Salemba Empat, cetakan pertama.

Sugiyono. 2014. Metode Penelitian Pendidikan Pendekatan Kuantitatif, Kualitatif dan R\&D. Bandung: Alfabeta.

Swarbrooke dan Horner.2007.Customer Behavior in Tourism, Second Edition, Oxford:Butterworth-Heinemman

Tien-Ming Cheng1 and Chiang-Chuan Lu2. 2013. Destination Image, Novelty, Hedonics, Perceived Value, and Revisiting Behavioral Intention for Island Tourism. Asia Pacific Journal of Tourism Research. Vol. 18, No. 7, 766783

UN World Tourism Organization (UNWTO) (2012) Why Tourism? [Website], diambil dari http://www2.unwto.org/en 1/03/20138, diakses pada 1 Maret 2018

Yoeti, Oka A. 2008. Perencanaan dan Pengembangan Pariwisata. Penerbit PT. Pradnya Paramita, Jakarta

Yoon, Yooshik dan Uysal, Muzaffer. 2005. An examination of the effects of motivation and satisfaction on destination loyalty: a structural model. Tourism Management 26, Pages 45-56, 2005. 